\title{
Austrian economics without extreme apriorism: A critical reply
}

\author{
Jonas Lipski ${ }^{1}$
}

Received: 5 October 2020 / Accepted: 4 June 2021 / Published online: 22 June 2021

(C) The Author(s) 2021

\begin{abstract}
In this paper I will analyze and criticize Linsbichler's recent proposition to interpret the fundamental axiom of Praxeology as analytic. I will first describe Linsbichler's problem situation. I will then describe and criticize Linsbichler's proposed solution to his problem; namely his interpretation of the fundamental axiom as analytic. I will argue that this idea does not fully utilize critical potentials that are available to improve the fundamental axiom. I will propose an alternative interpretation which I call the 'critical interpretation' that conserves the progressive aspects of Linsbichler's proposal while eliminating undesirable ones.
\end{abstract}

Keywords Austrian economics · Philosophy of economics · Praxeology · Critical rationalism

\section{Introduction: Linsbichler's problem}

In his "Austrian economics without extreme apriorism: Constructing the fundamental axiom as analytical", Alexander Linsbichler tries to resolve a gridlocked state of discussion within economics, namely the lack of fruitful discourse between 'Austrian' economists that participate in the praxeological tradition and economists from other traditions. The situation that Linsbichler wants to resolve can be described as follows: On the one hand Praxeology is often considered as an idiosyncratic enterprise that lacks certain scientific standards by economists outside of this tradition. On the other hand economists that self-identify as Praxeologists believe that participants of other traditions are lacking crucial insights into the true foundations of economics, leading them to produce explanations and theories that are fundamentally flawed. This mutual disapproval results in a situation in which the results of praxeological research are not taken seriously in other traditions and results of other

Jonas Lipski

jonas.lipski@philos.uni-hannover.de

1 Leibniz Universität Hannover, GRK 2073 "Integrating Ethics and Epistemology of Science"

(Founded By the Deutsche Forschungsgemeinschaft), Hannover, Germany 
traditions are not taken seriously in praxeological research. Linsbichler identifies the roots of this situation in the common conception of the philosophical arguments that are usually utilized to establish Praxeology. ${ }^{1}$ He therefore aims at developing a novel philosophical justification for Praxeology. This novel justification is supposed to enable fruitful discussion between Praxeologists and participants of other traditions. To accomplish this it has to be acceptable from the perspective of Praxeologists as well as from the perspective of other traditions.

\section{Classical justification's of praxeology}

'Praxeology' as defined by Ludwig von Mises denotes the practice to construct theories and explanations in the social sciences by employing a specific fundamental axiom. This axiom states that "Human action is purposeful behavior". This is clarified further by Mises who states that the meaning of this statement is "Action is will put into operation and transformed into an agency, is aiming at ends and goals, is the ego's meaningful response to stimuli and to the conditions of its environment, is a person's conscious adjustment to the state of the universe that determines his life" (Mises, 2007[1949], p. 11). Theorems derived from this axiom are supposed to be central to every explanation of social phenomena in praxeological research. The philosophical problem connected to this practice is that the fundamental axiom, while being a supposedly descriptive statement, does not have any obvious empirical content, meaning that it can neither be verified nor falsified directly by observational statements. Nevertheless Mises attempted to demonstrate that Praxeology is the only sound method for economics and the social sciences, rejecting the claim that the lack of empirical content constitutes a reason to abstain from using the fundamental axiom. Mises attempted to justify this claim by constructing different (at times mutually exclusive) arguments in favor of it. Mises argued that the fundamental axiom can be proven by introspection (see Mises, 2007, p. 39 or Mises, 1933, p. $122)^{2}$ or that it cannot be refuted due to its status as genetically or culturally determined presupposition of thinking (see Mises, 1962); in his (2017) Linsbichler also plausibly argues that some conventionalist' arguments can be found in Mises's writings. Without going into the details of Mises's arguments here, I want to point out that the common aim of these arguments is to justify an epistemically privileged status for the fundamental axiom as a principle that is to be accepted a priori. Thus the fundamental axiom, as well as theorems deductively derived from it, presumably cannot be criticized by any sort of empirical evidence. Since however Mises's arguments proved to be unsound (see Linsbichler, 2017 for refutations of Mises's different attempts), many economists came to be deeply suspicious of the proposed a

\footnotetext{
1 See Linsbichler (2017) for a summary and critique of these arguments.

2 Somewhat similar and connected to this, in his Human Action Mises claims that The starting point of praxeology is not a choice of axioms and a decision about methods of procedure, but reflection about the essence of action."(Mises, 2007, p. 39). This essentialist argumentation can be found more prominently in Rothbard's writings on the subject (see for example Rothbard, 1997, p. 64).
} 
priori status of the fundamental axiom as well as of Praxeology in general. ${ }^{3}$ This led to the gridlocked situation described above.

\section{Linsbichler's justification of praxeology}

Linsbichler's aim is to develop a consistent and philosophically acceptable justification of Praxeology. He intends to achieve this goal by arguing that the fundamental axiom ought to be interpreted as an analytic statement, inviting a conventionalist justification of Praxeology. Linsbichler argues (a) that there is an uncontroversial version of conventionalism that escapes many well-known criticisms voiced against conventionalist strategies and (b) this uncontroversial version of conventionalism can be applied to justify praxeology.

Linsbichler characterizes conventionalism as the practice of fixing the truth value of at least one statement so that "[...] neither observation nor intuition are a critical standard by which to falsify, verify, confirm, disconfirm, or corroborate it" (Linsbichler, 2019, p. 12). If evidence that contradicts a conventionalist theory is accepted, the truth value of the fixed statements might stay fixed by two different strategies according to Linsbichler. First, contradicting statements could simply be discarded. Linsbichler rejects this strategy because it leads to dogmatic tendencies in obvious ways. Second, this might be achieved by changing the semantics of the terms in question so that the result of the changes is that the beforehand fixed statements remain true. Following this strategy means that statements contradicting a conventionalist theory can be accepted as true, but the contradiction will have to be resolved not by modifying the fixed statements but by reinterpreting the terms that led to the contradiction. This strategy is less problematic than the first one, as Linsbichler points out (see ibid. p. 13).

According to Linsbichler, conventionalism comes with two necessary features: "(I) The conventions could in principle have been chosen differently [...] (II) The conventions are not justified by observation or intuition, but by pragmatic arguments for the superior expediency of the resulting theory or research programme". He adds to this that "(III) Conventions are restricted to sentences that do not exclude any potentially observable states of affairs" (ibid. italics in the original). The third feature serves the purpose of ruling out the use of conventionalism to indefinitely uphold sentences that directly contradict empirical findings; Linsbichler hopes that this renders the version of conventionalism that he advocates as uncontroversial. This version of conventionalism only allows for fixing the truth value of statements that are not empirically falsifiable, meaning the set of contradicting statements does not include any statement that refers to an observable state of affairs.

All this connects to Praxeology as it is described above. Praxeologists claim that their fundamental axiom cannot be falsified and that therefore theorems derived from that axiom are immune to empirical criticism. The unsatisfying arguments

\footnotetext{
3 Blaug's pejorative remarks towards Mises's methodological ideas in his (1980, p. 91ff) exemplify this stance towards Praxeology.
} 
that where constructed to defend this claim led to the gridlocked situation described above. Linsbichler aims at resolving this situation by using his version of conventionalism to justify Praxeology. In order to do so, Linsbichler argues that the fundamental axiom can be interpreted as analytic. This, if successful, would lead feature (III) to be satisfied since the truth value of analytic statements is not dependent upon empirical findings. He develops two arguments to establish the claim that the fundamental axiom can be treated as analytic. First, he argues that the fundamental axiom indeed has no empirical content, meaning that it does not forbid any observable state of affairs. Linsbichler points out that while accepting the fundamental axiom means to attribute theoretical entities to individuals but not to other observable objects, this attribution is not based on observable differences: "Man acts and inanimate objects merely behave. However, there is no obvious observable difference between acting and behaving-rather the social scientist has to start with a methodological decision, which kind of explanations she regards satisfactory." (Linsbichler, 2019, p. 14, italics in the original). Second, he argues that the interpretation of the fundamental axiom as analytic corresponds to the use of terms in everyday language. While this of course is "[...] no guarantee for scientific progress [...] we may welcome that Mises' depiction of "the fundamental law of action" is true by virtue of the usual meanings of its terms in everyday language [...]" according to Linsbichler (ibid.).

If these arguments are accepted and the fundamental axiom is interpreted as analytic, this ought to solve Linsbichler's problem in the following way. Linsbichler's solution has two directions; it is "double-edged" (Linsbichler, 2019, p. 27). As he points out, it is a methodological decision that leads to accepting the fundamental axiom. For the side of defenders of Praxeology this has the following consequences: Since this initial decision could be made in some other way, conventionalist minded Praxeologists cannot deny the scientific status of other traditions without closely studying them. They will have to engage in critical argumentation in order to demonstrate the pragmatic superiority of their research program. But this is equally valid for the side of researchers working in different traditions: They cannot discard praxeology by referring to the philosophically unsound justifications underlying it anymore. Instead, they too have to engage in critical argumentation about the pragmatic virtues of Praxeology (see ibid.).

Therefore, it seems like Linsbichler has found a way to resolve his problem by showing a way to participate in the tradition of Praxeology while also participating in the broader context of scientific discussions between proponents of different traditions within economics.

\section{Controversial consequences of uncontroversial conventionalism}

I want to point out two controversial consequences of Linsbichler's solution. The first one is connected to the effect that the acceptance of his solution would most likely have in economic practice. I will argue that in practice Linsbichler's solution will make fundamental changes of the content of the fundamental axiom extremely unlikely and thus inhibit theoretical progress. While this is likely to happen in practice, it is not a necessary consequence of Linsbichler's solution if 
it is interpreted as sufficiently open. This interpretation however leads to the second controversial consequence. That is that Linsbichler's solution fails to incentivize using the various means of criticizing behavioral assumptions available in the context of economics. I will propose an alternative to Linsbichler's solution that avoids these consequences while conserving the progressive aspect of his solution.

As I have pointed out above, the conventionalist' justification advocated by Linsbichler clearly encourages comparative evaluations of Praxeology to other traditions of economic theorizing. Thus if another tradition turns out to have some desirable properties that Praxeology lacks, the fundamental axiom will be critically examined and possibly modified or even rejected. Nevertheless under certain circumstances Linsbichler's solution fails to provide an incentive to criticize the fundamental axiom in the absence of a competing tradition that is assumed to be superior to Praxeology. Economists practicing Praxeology are committed not only to the a priori status of the fundamental axiom, but also to its specific content as it is described above. Given this situation the acceptance of Linsichler's idea appears to provide no incentive to modify the fundamental axiom even in the face of theoretical or empirical problems connected to explanations that include Praxeological theorems. This is so since Linsbichler's justification preserves an epistemically privileged status for the fundamental axiom. Therefore if some theory or explanation that involves praxeological theorems appears to be problematic for some reason, for example if it is inconsistent with observational statements, the fundamental axiom will not to be modified in order to resolve the inconsistency. Other involved statements might be modified at will; but the fundamental axiom and the theorems that are validly derived from it ought to be kept stable. This is a consequence of the conjoined commitment towards the a priori status as well as the content of the fundamental axiom.

I take this to be undesirable for the following reasons. As Linsbichler points out in his paper, the fundamental axiom is not infallible (see Linsbichler, 2019, p. 27). This means that it is possible that alternatives exist that are preferable to the fundamental axiom on pragmatic grounds. Linsbichler's justification of Praxeology gives no incentive for Praxeologists to actively search for these alternatives. Therefore an interpretation of the fundamental axiom that encourages this search while preserving the progressive aspects of the conventionalist' interpretation ought to be preferred over Linsbichler's solution. I will argue below that such an interpretation indeed is viable.

While the inhibition of theoretical progress that I have described above is not a necessary consequence of Linsbichler's idea, it is a consequence that is not only likely to appear in practice but that is also to some extent supported by his discussion. In one of the two arguments that he proposes in favor of his interpretation of the fundamental axiom as analytic he connects the content of the fundamental axiom to the meaning of the involved terms in ordinary language (see Linsbichler, 2019 , p. 14). This however is only sound given the currently upheld interpretation of the fundamental axiom. Thus Linsbichler's interpretation of the fundamental axiom as analytic is at least weakly tied to the currently upheld interpretation of the content of the fundamental axiom. This invites the problem that I have described above. 
However it has to be emphasized that this is by no means a necessary consequence of Linsbichler's idea. ${ }^{4}$ The connection to ordinary language that Linsbichler uses to support his interpretation only plays a minor role in his overall argument. He clearly advocates the possibility of modifying the fundamental axiom by reinterpreting the meaning of the involved terms (see Linsbichler, 2019, p. 15). Also he expresses an overall anti-dogmatic attitude throughout his (2017). Thus Linsbichler's intent is captured better if his proposal is interpreted as advocating the analyticity of the fundamental axiom without fixing its meaning on the methodological level. This means that as a methodological heuristic Linsbichler's justification does not prohibit any interpretation of the fundamental axiom, including those that are inconsistent with its current interpretation.

This interpretation of Linsbichler's argument does not invite the rather extreme inhibition of progress generated by traditional defences of praxeology. Nevertheless a less extreme inhibition remains as a consequence of interpreting the fundamental axiom as analytic. While Linsbichler is correct in pointing out that the fundamental axiom is consistent with any possibly observable state of the world and thus cannot be tested empirically in isolation, this fact in itself does not prohibit empirical testing. Empirical testing situations are usually underdetermined, meaning that in the case of an inconsistency between a prediction derived from a set of statements and an observational statement it cannot be determined which subset of the set of statements is 'responsible' for the inconsistency. ${ }^{5}$ One way to gain knowledge about this 'responsibility' is to tentatively revise some subset of the initial set of statements. If a praxeological theorem were to be involved in such a situation, Linsbichler's solution would now prohibit revising the respective theorem or the fundamental axiom from which it is derived. This is so because if the fundamental axiom is thought of as analytic, it does not have any descriptive content and is thus not criticizable by any sort of empirical testing. This however is not a necessary consequence of the fact that the fundamental axiom in isolation is consistent with all possibly observable states of the world. Even if this is accepted, one can propose to leave open the possibility of revising or refuting the axiom in a given a testing situation as it is described above. The immunity of the fundamental axiom in this scenario is a consequence exclusively of the decision to interpret it as analytic. Therefore, Linsbichler's solution rules out a possible means of fruitfully criticizing and revising the fundamental axiom.

The situation is very similar when the potential relation between psychology and Praxeology is considered. Analytic statements have no descriptive content. Therefore Linsbichler's solution fails to incentivize the comparison of the fundamental axiom to descriptive theories as they are developed in the context of psychology. Yet as I will argue in the next section, such direct comparisons proved to be very fruitful in the recent history of economics; thus this consequence of Linsbichler's interpretation is undesirable.

\footnotetext{
${ }^{4}$ I am grateful to the anonymous reviewer for pointing this out to me.

5 This is often referred to as the Duhem-Problem in the context of the Philosophy of Science.
} 
Again it has to be emphasized that Linsbichler's interpretation does by no means strictly prohibit an influence of psychological findings on the fundamental axiom or its revision as a consequence of indirect testing. The axiom might be reinterpreted in its meaning as a consequence of the analyses of descriptive psychological theories or testing situations. The problem with Linsbichler's interpretation is rather that is does not provide a positive incentive to engage in this kind of criticism. As many prominent philosophers of science have argued, methodological ideas serve a heuristic function in research practice (see for example Mantzavinos 2018[2016], p. 170). Interpreting the fundamental axiom as analytic does not incentivize to criticize it by referring to descriptive theories or in the context of empirical testing situations.

To summarize this: The second controversial consequence of Linsbichler's interpretation is that it does not fully utilize the critical potentials that can be drawn from empirical testing situations and descriptive psychological theories.

In the next chapter I will argue that an alternative interpretation of the fundamental axiom is viable that avoids the controversial consequences of Linsbichler's interpretation while preserving its desirable features.

\section{The critical interpretation: The fundamental axiom as descriptive and indirectly testable}

I propose that the problems described above can be circumvented if the fundamental axiom is interpreted as a synthetic statement that is subject to indirect empirical testing. Given this interpretation, the fundamental axiom would lose its epistemically privileged status within the Austrian School. ${ }^{6}$ As a synthetic statement, I propose interpreting its content as consisting of a cognitive assumption and of a motivational assumption (see Mantzavinos 2004 [2001], chapter 1). The motivational assumption consists of the idea that human action always aims at some unspecified goal. The cognitive assumption consists of the idea that humans chose among different alternatives to attain this goal. ${ }^{7}$

Given this interpretation, the fundamental axiom might be modified or refuted as a consequence of testing situations as they are described above. There ceases to be an obstacle on the methodological level preventing such behavior. Since the fundamental axiom is just one descriptive assumption among others, an inconsistency between a set of statements involving praxeological theorems and an observational statement might very well be resolved by modifying the fundamental axiom. It might also lead to its refutation. Also this interpretation encourages the critical comparison of psychological theory and the content of the fundamental axiom. Both motivational and cognitive mechanisms of individuals are the subject of psychological

\footnotetext{
6 Thus while Linsbichler proposes to preserve the a priori status of the fundamental axiom on the cost of its descriptive content, I believe it more fruitful to preserve its descriptive content on the cost of its a priori status.

7 This cognitive assumption does not follow directly from Mises's more abstract formulations of the fundamental axiom; however I believe it uncontroversial that he as well as other Praxeologists always endorses when applying the fundamental axiom.
} 
theory; thus since the fundamental axiom describes such mechanisms, its content is to be compared to the potential alternatives developed in the context of psychology.

In this context it is important to point out that the strategies descripted above were actually applied in the recent economic history and led to progressive theoretical changes. The writings of Douglass North and Chrysostomos Mantzavinos provide outstanding examples for this. North discovered that theories and explanations based on traditional rational choice theory lacked empirical success (see Mantzavinos, 2021, p. 52). He reacted to this by attempting to modify the behavioral assumptions employed in rational choice theory and to actively compare these to theories developed in the context of cognitive science. This strategy ultimately led to him rejecting rational choice theory as well as to his theoretical views on the importance of institutions and institutional change for understanding economic growth (see North, 2002[1990] as well as North, 2005). Similarly, Mantzavinos's (2004[2001]) is motivated by the failure of various different traditions in economics to successfully explain the emergence of institutions. ${ }^{8}$ He reacted to this by proposing a model of individual cognition derived from cognitive science that enabled him to successfully explain the emergence of institutions. While these examples are not directly connected to the Austrian School, Mantzavinos and North clearly interpreted fundamental behavioral assumptions as being subject to criticism through empirical testing as well as through comparison to psychological findings. ${ }^{9}$ This led to important theoretical progress. I believe that this strategy could be fruitfully mimicked within the Austrian School. For the reasons presented above, the apriorism connected to Praxeology seems to be a major obstacle to this, even in its philosophically sound version as it is advocated by Linsbichler.

If my proposed interpretation is accepted, both the motivational as well as the cognitive assumption that underlie the fundamental axiom are opened up to criticism derived from psychological research. Take as an example for this the cognitive assumption implicit to the fundamental axiom. As I proposed above, it states that actions always involve choosing among different alternatives. Thus these alternatives have to be somehow constructed by the individual mind and the mind has to be able to single one of them out as the outcome of the process of choice. If cognitive scientists were to discover that the process of choice sketched in this way is only one among several processes that guide human action, this would mean that the fundamental axiom captures only one aspect of human action among others. Reconstructing the fundamental axiom so that the other respective processes are included in its content would then constitute an improvement that might lead to relevant implications for economic theory (as I mentioned above, North explicitly called for this and Mantzavinos applied this strategy in his (2004[2001])). Analogously, progress in explaining the process of motivation in individual human minds might be utilized

\footnotetext{
8 Including Hayek's attempts (see Mantzavinos, 2004[2001], p. 78).

9 Closely connected to the Austrian School, I believe the late works of F.A. Hayek to provide an example for employing a similar strategy, especially if his (2003[1982]) as well as his (1988) and their connection to his (2014[1952]) are considered. The exegesis of Hayek's writings as well as his connection to the Austrian School are however subject to controversy. I believe (Scheall, 2020) to strengthen the interpretation of Hayek's work as an instantiation of the strategy described above.
} 
to improve the fundamental axiom. If for example a well corroborated theory about human motivation were available within psychology, the fundamental axiom ought to be reconstructed in order to capture those insights from that theory that are relevant for economics.

The interpretation of the fundamental axiom that I propose ought to be preferred over Linsbichler's relative to a specific philosophical framework. This framework is the idea of 'pancritical rationalism' as it has been developed by W.W. Bartley (1984[1962]). One element of this framework is the idea that theories ought to be exposed to a maximally critical environment in order to stimulate progress (ibid. p. 169). As H. Albert pointed out, this means that possible critical potentials of seemingly unrelated ideas ought to be utilized by constructing methodological principles that allow for connecting the respective ideas to one another in fruitful ways (see Albert, 2010[1968], p. 91). The interpretation of the fundamental axiom proposed above uncovers the potential of empirical testing to improve the fundamental axiom as well as actively encourages the connection of psychology to praxeology. Therefore it ought to be preferred over Linsbichler's interpretation within the framework of pancritical rationalism.

The proposed interpretation of the fundamental axiom encourages the critical comparison between different traditions in economics to the same extent as Linsbichler's interpretation does. It adds to Linsbichler's interpretation a positive incentive towards empirical and theoretical criticism of the fundamental axiom. It thus preserves Linsbichler's achievement while further strengthening the critical attitude that also motivated Linsbichler's approach.

\section{The Austrian School without apriorism}

The interpretation of the fundamental axiom proposed above would deprive the fundamental axiom of its epistemically privileged status. The 'fundamental axiom' ceases to be 'fundamental' in an epistemological sense; Praxeology would therefore not include any specific a priori principle anymore. It might be argued that this takes away a defining characteristic of Praxeology and therefore means to effectively reject Praxeology. ${ }^{10}$

In reply to this I want to point out that one major motivation behind justifying the fundamental axiom as a priori principle seems to be the intent to justify its practical application in economic theorizing as scientifically legitimate. In his (1933) Mises apparently saw no reason to justify the employment of the fundamental axiom in any other way then by pointing out its central role and its merits constructing economic explanations and theories. In his (1962), which contains the most explicit and elaborate defense of the a priori status of the fundamental axiom, he attempted to defend its use against inductivist' and falsificationist' demarcation criteria (see

${ }_{10}$ Again I am grateful to the anonymous reviewer that pointed this out to me. 
Mises, 1962, p. 69). ${ }^{11}$ The goal behind introducing apriorism to Austrian Economics can thus also be achieved by the interpretation proposed above: As many (if not all) assumptions used in science, the employment of the fundamental axiom is justified exclusively by its explanatory and empirical merits. This is clearly also advocated by Linsbichler; but I think from this it follows that there is no further need to attribute any special status to the fundamental axiom even if this means to break with traditional Praxeology. ${ }^{12}$

\section{Conclusion}

I have argued that Linsbichler's interpretation of the fundamental axiom does not fully utilize the possibilities to generate theoretical progress via criticism. Linsbichler's methodological approach provides a great improvement over the classical methodological arguments that Mises developed, as well as over the attempts that were developed by his followers. However, it comes with some undesirable consequences. I have proposed an alternative to his interpretation that presumably preserves the progressive aspects of his idea while further strengthening the critical intentions underlying it.

My argument was led by the conviction that methodologies ought to provide heuristics that support the growth of knowledge. My approach therefore differs on a general level from Linsbichler's, who tries to find a sound methodological justification for Praxeology. This shift in perspective from discussing the justification of the epistemological status of scientific principles towards discussing the heuristic consequences that competing approaches to epistemology have on research proved to be fruitful. It allowed for introducing scientific progress as a critical standard to the contemporary debate.

Acknowlegements I thank Philippe van Baßhuysen, Uljana Feest, Alexander Linsbichler and Chrysostomos Mantzavinos for helpful discussions of the arguments proposed in earlier versions of this paper. The research for this paper was funded by the Deutsche Forschungsgemeinschaft (DFG) as part of the research training group GRK 2073 Integrating Ethics and Epistemology of Scientific Research.

Funding Open Access funding enabled and organized by Projekt DEAL.

Open Access This article is licensed under a Creative Commons Attribution 4.0 International License, which permits use, sharing, adaptation, distribution and reproduction in any medium or format, as long as you give appropriate credit to the original author(s) and the source, provide a link to the Creative Commons licence, and indicate if changes were made. The images or other third party material in this article are included in the article's Creative Commons licence, unless indicated otherwise in a credit line to the material. If material is not included in the article's Creative Commons licence and your intended use is

\footnotetext{
11 Of course Mises often misunderstood and misrepresented the respective ideas behind these criteria (see for example (Di Iorio 2008) for Mises's misrepresentations of Popper's views).

12 Breaking with Praxeology of course does not mean to break with the Austrian School. Authors within the Austrian School are connected through a multitude of practices that are independent of apriorism. To name just a few examples consider the commitments to non-idealized representations, methodological individualism or subjectivism.
} 
not permitted by statutory regulation or exceeds the permitted use, you will need to obtain permission directly from the copyright holder. To view a copy of this licence, visit http://creativecommons.org/licen ses/by/4.0/.

\section{References}

Albert, H. (2010[1968]). Traktat über kritische Vernunft. (english title: Treatise on Critical Reason). Tübingen: Mohr Siebeck.

Bartley, W. W. (1984[1962]). The Retreat to Commitment. Peru, Illinois: Open Court Publishing Company

Blaug, M. (1980). The methodology of economics or how economists explain. Cambridge: Cambridge University Press.

Di Iorio, F. (2008) Apriorism and Fallibilism: Mises and Popper on the Explanation of Social Phenomena, Nuova Civiltà delle Macchine, n. 2

Hayek, F. A. (1988). The fatal conceit. The University of Chicago Press.

Hayek, F. A. (2003[1982]). Recht, Gesetz und Freiheit. (english title: Law, Legislation and Liberty) Tübingen: J.C.B. Mohr (Paul Siebeck).

Hayek, F. A. (2014[1952]). The Sensory Order. Mansfield Centre: Martino Publishing.

Linsbichler, A. (2017). Was Ludwig von Mises a conventionalist?-A new analysis of the epistemology of the Austrian School of economics. Palgrave Macmillan.

Linsbichler, A. (2019). Austrian economics without extreme apriorism: Constructing the fundamental axiom as analytical. Synthese. https://doi.org/10.1007/s11229-019-02150-8

Mantzavinos, C. (2004). Individuals, institutions and markets. Cambridge University Press.

Mantzavinos, C. (2018). Explanatory pluralism. Cambridge University Press.

Mantzavinos, C. (2021). A dialogue on institution. Springer.

Mises, L. (1933). Grundprobleme der Nationalökonomie. Jena: Verlag von Gustav Fischer. http://old. mises.de/public_home/article/72

Mises, L. (1962): The Ultimate Foundation of Economic Science. An Essay on Method, Princeton: D. Van Nostrand Company, Inc. https://mises.org/library/ultimate-foundation-economic-science

Mises, L. (2007). Human action. Liberty Fund.

North, D. (2002). Institutions, institutional change and economic performance. Cambridge University Press.

North, D. (2005). Understanding the process of economic change. Princeton University Press.

Rothbard, M. (1997). The logic of action 1-Method, money, and the Austrian School. Edward Elgar Publishing Limited.

Scheall, S. (2020). F. A. Hayek and the epistemology of politics-The curious task of economics. Routledge.

Publisher's Note Springer Nature remains neutral with regard to jurisdictional claims in published maps and institutional affiliations. 